\title{
ACCESORIOS METÁLICOS DE CORREAS DE CINTURONES MILITARES ALTOIMPERIALES HALLADOS EN HISPANIA
}

\author{
POR \\ JOAQUÍN AURRECOECHEA FERNÁNDEZ \\ Universidad de Málaga ${ }^{1}$
}

PALABRAS CLAVE: Equipo militar romano. Cinturones militares romanos. Bronces romanos. Pinjantes romanos. Ajuar de Aznalcázar. Sevilla (provincia). Teba. Málaga (provincia). Campamento de Herrera de Pisuerga. Palencia (provincia). Museo Arqueológico Nacional de Madrid.

KEY WORDS: Roman military equipment. Roman military approns. Roman bronzes. Roman pendants. Grave-goods of Aznalcázar. Sevilla (province). Teba. Málaga (province). Military camp of Herrera de Pisuerga. Palencia (province). Museo Arqueológico Nacional of Madrid.

\section{RESUMEN}

Estudio sobre los accesorios metálicos pertenecientes a «mandiles» militares de época romana hallados en Hispania. Entre ellos se documenta un conjunto completo aparecido en una tumba de Aznalcázar (Sevilla), hallazgo de excepcional importancia debido a la escasez de piezas semejantes en contextos sepulcrales. Finalmente, se interpreta el significado de estos bronces dentro del marco cronológico de la dinastía flavia.

\section{SUMMARY}

Study of roman military «aprons» found in Hispania, specially the specimens discovered in a tomb in Aznalcázar (prov. of Seville). This group is of special relevance due to the fact that there are very few pieces of this kind in funerary contexts.

El equipo militar romano ha sido uno de los temas más desatendido por los investigadores españoles. Hasta hace sólo unos años apenas se sabía nada de él, salvo los trabajos realizados por Schulten y otros arqueólogos alemanes en campamentos republicanos. Este vacío de investigación contrastaba con la escasa pero constante aparición de esta clase de objetos en territorio hispano ${ }^{2}$. El panorama esbozado ha evolucionado en los últimos tiempos, pa-

\footnotetext{
I jaurreco@uma.es

2 Incluso en zonas como la Meseta Sur, alejada de las actividades bélicas que se desarrollaban en nuestro suelo ( $\mathrm{Au}$ rrecoechea, 1995/96).
}

ralelo al aumento de las excavaciones practicadas en asentamientos militares y al interés creciente que la comunidad científica de nuestro país demuestra hacia este apartado de la arqueología peninsular ${ }^{3}$, aunque, la publicación de los materiales metálicos hallados aún no se ha desarrollado convenientemente ${ }^{4}$.

Nuestra línea de investigación a largo plazo es la elaboración de una síntesis sobre el tema, si bien es necesaria una fase previa de catalogación, momento en el que actualmente estamos. Como el estudio de los objetos encontrados en excavacíones científicas recientes está asegurado, ya que se publicarán en los correspondientes informes de excavación, nos hemos centrado en los bronces procedentes de hallazgos antiguos y en los descontextualizados arqueológicamente. Para su localización iniciamos una exhaustiva búsqueda en museos y colecciones privadas. El elevado número de piezas encontradas nos impulsó a publicarlas paulatinamente, como por ejemplo hacemos con el presente artículo, dedicado a los accesorios metálicos pertenecientes a las correas auxiliares que partiendo del cinturón colgaban sobre el bajo vientre del soldado, para conformar lo que se ha venido a llamar el «delantal» militar ${ }^{5}$. El interés de estas piezas es doble, pues es la primera vez que se documentan ejemplares de esta índole en

\footnotetext{
${ }^{3}$ Prueba de ello es el importante avance conseguido en el conocimiento de los campamentos de época augustea y julioclaudia originados en las Guerras Cántabras (29-19 a.C.), entre ellos Herrera de Pisuerga (Legio IIII Macedonica y ala Parthorum), León (Legio VI Victrix y Legio VII Gemina), Astorga (Legio X Gemina) y Rosinos de Vidriales (Legio X Gemina). Simultáneamente se han dado a conocer nuevos campamentos temporales, así el de Andagoste (Álava) y Espina del Gallego (Cantabria), o los asentamientos de auxiliares de Villalazán (Zamora) y Burgo de Osma (Soria). Para completar este renovado interés por la arqueología militar baste también citar la continuación de las excavaciones en enclaves militares gallegos (Aquis Querquennis y A Cidadela), o la reapertura de los trabajos en Numancia.

${ }^{4}$ Existe algún caso aislado, como por ejemplo las excavaciones en Herrera de Pisuerga que nos han proporcionado algunas piezas metálicas publicadas (Pérez, 1995; García Díez, 1999; Illarregui, 1999), aunque el grueso de los materiales están aún inéditos.
} 

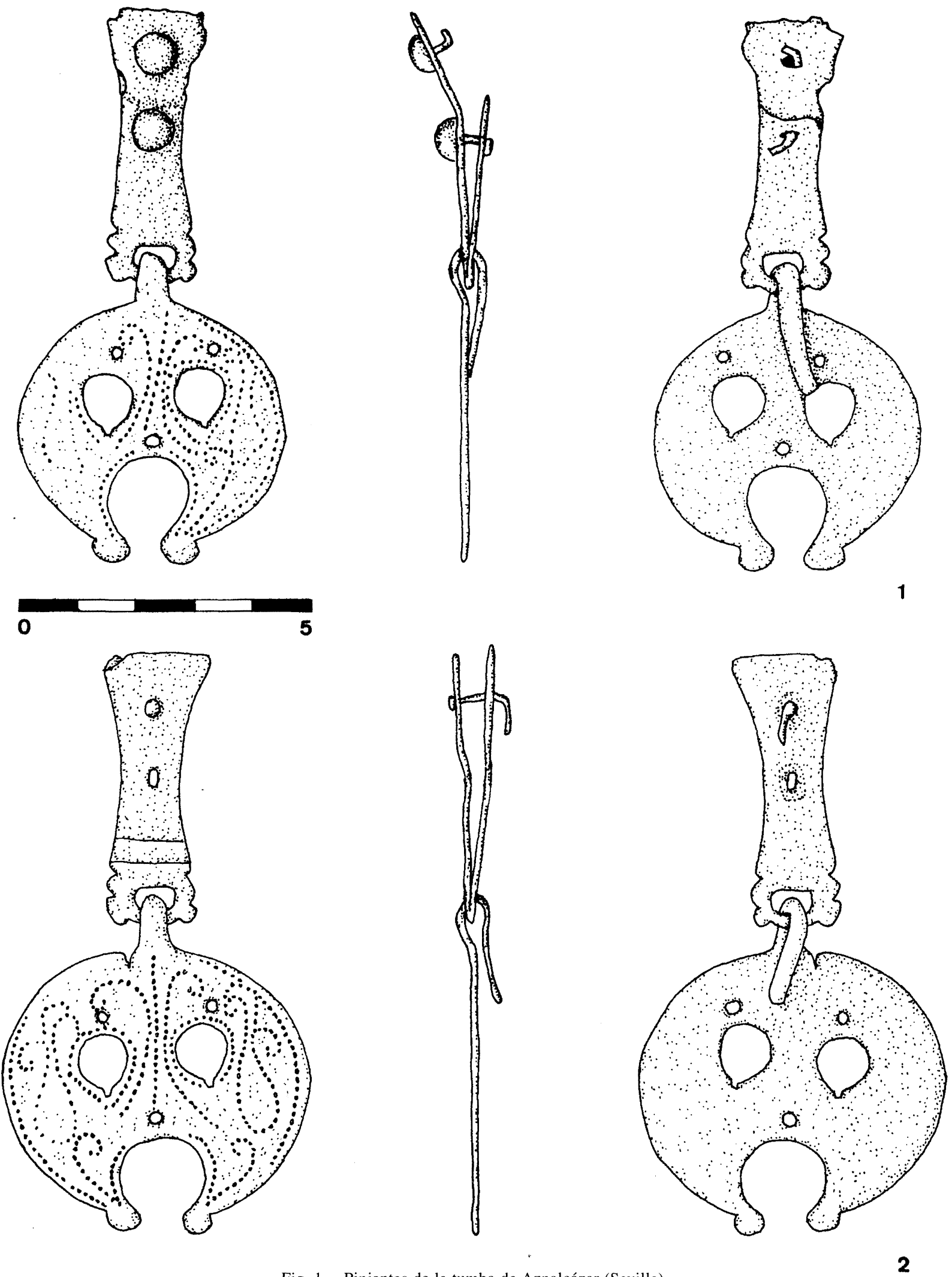

Fig. 1.-Pinjantes de la tumba de Aznalcázar (Sevilla). 


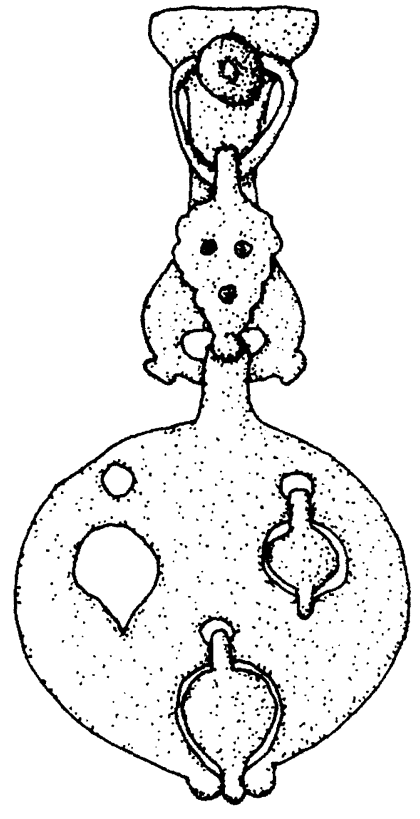

1

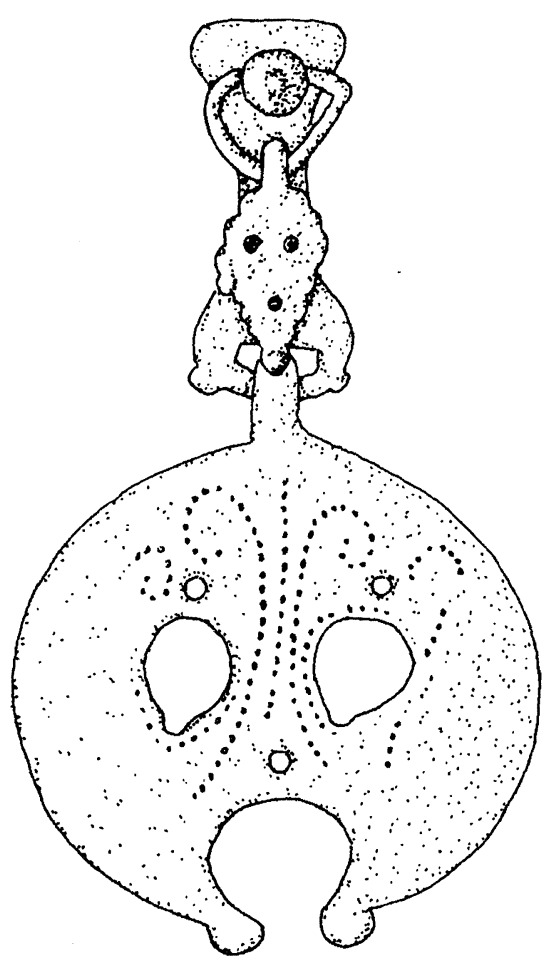

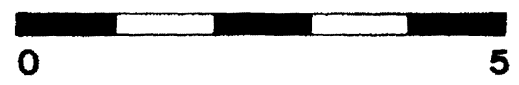

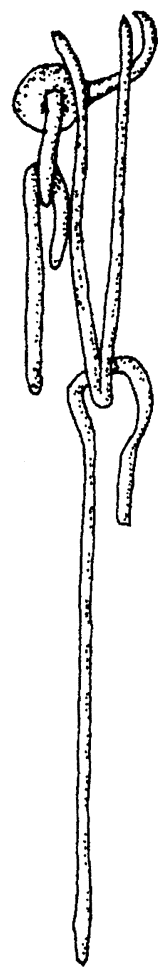

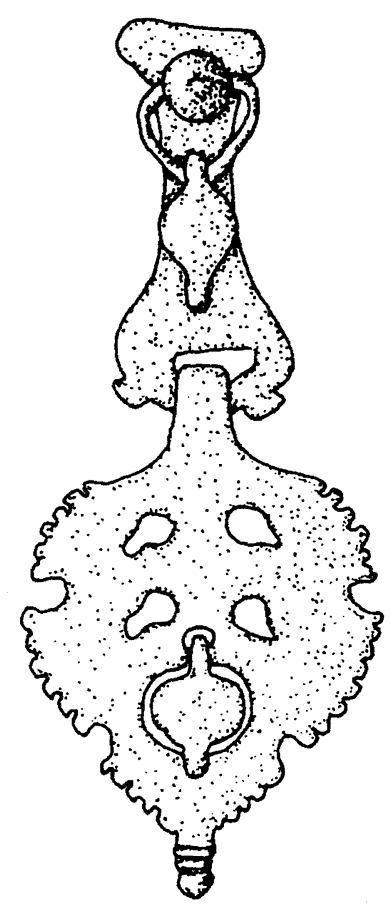

2

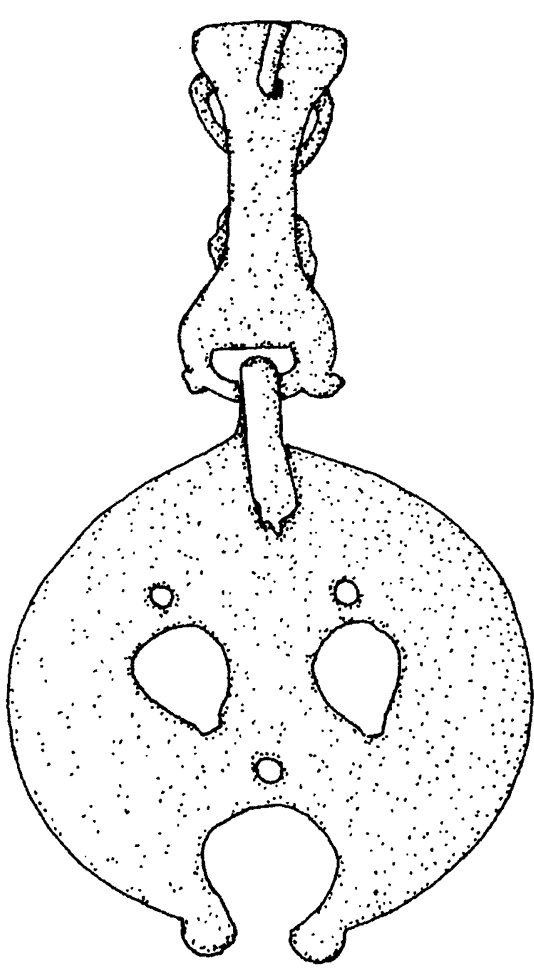

3

Fig. 2.-Pinjantes de la tumba de Aznalcázar (Sevilla). 

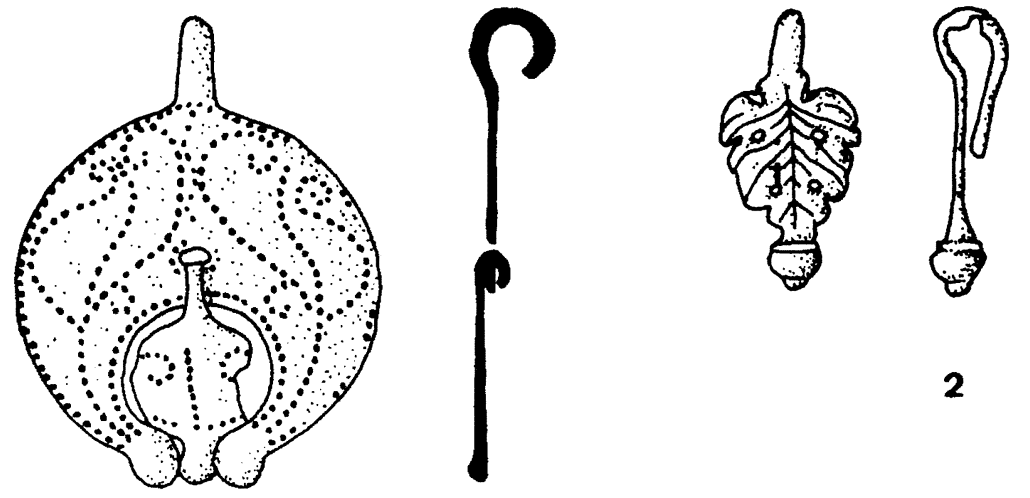

2

1
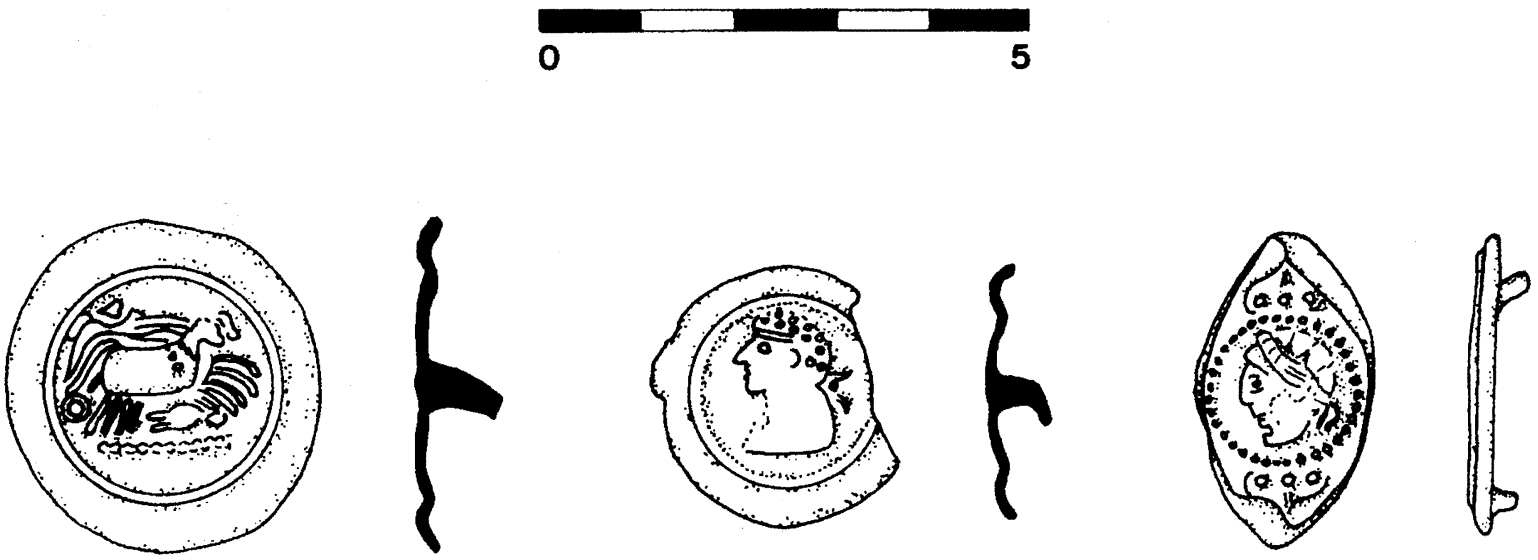

3

4

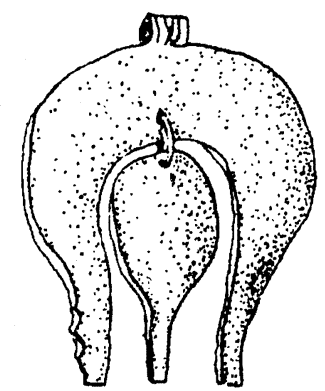

6
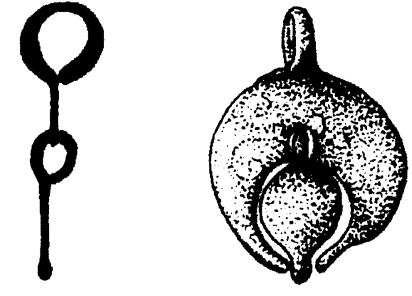

7

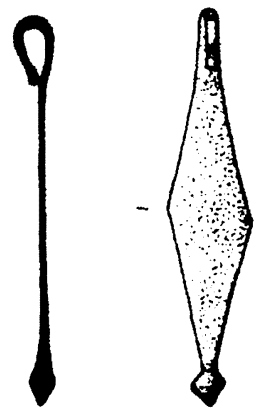

8

Fig. 3.-1 a 5, procedentes de Teba (Málaga). 6, hallado en la provincia de Palencia (según Thouvenot). 7 y 8 , encontrados en Herrera de Pisuerga (según Pérez). 
Hispania y, además, los bronces militares de uso personal datables en la primera centuria no son muy abundantes en nuestra provincia, al menos en nuestra fase actual de estudio.

\section{CATÁlOGO Y CONTEXTO ARQUEOLÓGICO}

De Aznalcázar (Sevilla) procede un conjunto completo de terminales encontrados fortuitamente a principios de los años 60, mientras se hacían faenas agrícolas. Formaban parte del ajuar de una tumba atribuible a un soldado, junto a un anillo de oro decorado con un entalle que representa a Minerva. Lamentablemente la información adicional que se posee sobre el hallazgo es muy escasa, ya que se desconoce tanto la forma como los materiales de construcción del enterramiento. Los objetos fueron entregados a las autoridades pertinentes quienes los depositaron en el Museo Arqueológico de Sevilla, lugar donde actualmente se conservan ${ }^{6}$. Tanto la falta de la hebilla del cinturón como de los apliques de las correas, nos llevan a pensar que no se entregaron todos los materiales encontrados o que la sepultura había sido parcialmente violada. Respecto al enclave de Aznalcázar, se corresponde con la Olontigi de época romana, citada por Plinio cerca del río navegable Maenuba (Plinius, III, 12) y por Mela (III, 5), quien la califica de pequeña urbs. Olontigi acuñó monedas en lenguas íbera, romana y bilingües durante los siglos II-I a.C. (Sola, 1965, 9-26; Romagosa, 1969, 20-23). En su hinterland se han encontrados restos de una posible villa en Torres de Guadiamar y una necrópolis tardorromana en Los Naharros. Quizá un dato importante es que conserva un castillo medieval cuyo origen podría retrotraerse a una fortaleza romana anterior. Como perteneciente al enclave militar romano se ha querido reconocer una de las puertas del recinto, construida con arcos de medio punto unidos por bóvedas de cañón y una posible torre de flanqueo. La importancia estratégica de la fortaleza habría ocasionado su reconstrucción en época musulmana, periodo en el que alcanzó gran importancia (Hernández; Sancho; Collantes, 1938, 182-186). La ciudad debió perdu-

5 Traducción al español de los términos en inglés «aprón» y alemán «Hängeschurz» (delantal, mandil), usados por los investigadores de estas nacionalidades. Los arqueólogos franceses lo denominan simplemente como «correas auxiliares de cinturón».

${ }^{6}$ Expediente de entrada fechado el 20 de octubre de 1963, números de inventario 11145 a 11149 . Queremos agradecer a D. F. Fernández Gómez, director del museo, la oportunidad brindada al darnos a conocer estas piezas y las facilidades ofrecidas para su estudio. rar en tiempos visigodos, como atestigua la necrópolis perteneciente a este momento documentada gracias a una rica colección epigráfica (Corpus, 1996, 21-28).

El hallazgo sevillano consta de 5 pinjantes unidos a una placa para asirse al cuero (figs. 1 y 2). Cuatro de ellos son luniformes y están complementados mediante sendos colgantes secundarios en forma de «gota», mientras que el ejemplar que remata el conjunto presenta el aspecto de una hoja vegetal. Todas las piezas, a excepción de la última mencionada, debieron contar con una decoración realizada en frío mediante la técnica del punzonado, si bien el excesivo desgaste de algunos ejemplares impide apreciar actualmente dicha ornamentación. Restos de un baño de plata puede aún observarse en las zonas menos desgastadas.

Otro lote de piezas que analizaremos proceden de prospecciones superficiales en la zona de Teba (Málaga), sin que podamos precisar el lugar exacto de aparición. Nos referimos a una lúnula similar a las aparecidas en Aznalcázar, pero mejor conservada, lo que nos permite apreciar la totalidad de la ornamentación punzonada y la presencia de abundantes restos de plateado, así como a un pinjante secundario en forma de hoja y tres apliques claveteados con decoración figurada (fig. $3, \mathrm{n}$. $^{\text {s }} 1-5$, y 4). En el término municipal de Teba conocemos habitats ibéricos desde el siglo viII a.C. en el yacimiento de «Los Castillejos» (García Alfonso, 1993-1994, 45-83; Recio, 1991-1992, 89-98). En época romana gozó de una rica vida urbana, como demuestran las estatuas públicas y privadas (Recio, 1988, 119-124; Rodríguez Oliva; Atencia, 1986, 227-245; Fernández Ruiz, 1981, 61-65), la epigrafía (Fernández Ruiz; Rodríguez Oliva, 1978, 55-60) y la aparición de diversos alfares, uno de ellos dedicado a producir terra sigillata (Serrano; Gómez; Castaños, 1992, 181-202), Todavía en el siglo VI d.C. el territorio estaba habitado, según se desprende de la necrópolis visigoda excavada en «El Tesorillo» (Serrano; Atencia; Luque, 1985, 117-162).

El campamento romano de Herrera de Pisuerga (Palencia) nos ha proporcionado otro par de ejemplares: un colgante luniforme y otro romboidal (fig. 3 , n. ${ }^{\text {os }} 7$ y 8 ). En este enclave arqueológico se superponen dos fuertes distintos, el de una legión (la Legio IIII Macedonica, 25 a.C./39 d.C.) y el de un ala auxiliar de caballería (el ala Parthorvm, segunda mitad de la primera centuria). Los accesorios pertenecientes a «delantales» militares fueron hallados en las excavaciones correspondientes al fuerte del ala Parthorvm, que se ubica sobre el antiguo castellum legionario, ocupando una superficie inferior al 
antiguo campamento (Pérez, 1996, 91-102). En las construcciones del ala Parthorm se reaprovechan materiales de la época anterior. Si a este último dato, nosotros le sumamos las dificultades de una excavación urbana (con remociones de tierra traídas de otros lugares) y la perduración de muchos objetos metálicos, podremos entender lo problemático que resulta discernir cuáles son los restos metálicos de los legionarios y cuáles pertenecieron a los equites del ala.

Por último queremos mencionar un pinjante publicado en un antiguo catálogo del Museo Arqueológico Nacional (Thouvenot, 1927, 130, n. ${ }^{\circ}$ 667) como procedente de la provincia de Palencia, sin que sepamos el lugar exacto del hallaz-

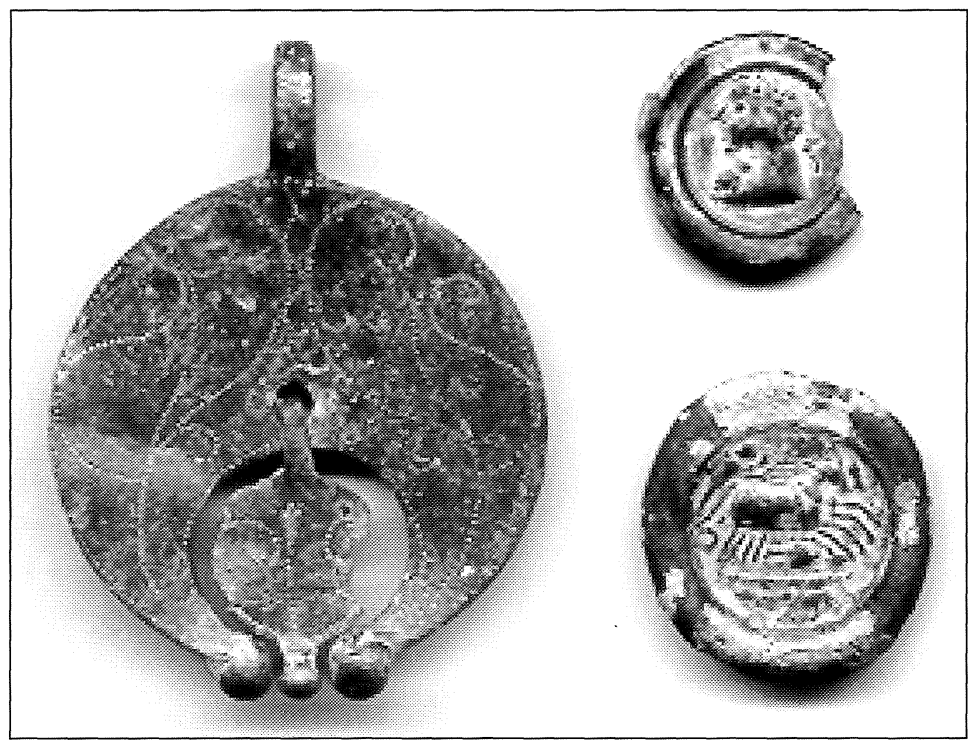

Fig. 4._Accesorios para «delantales» de Teba (Málaga). go (fig. 3, n. $^{\circ}$ ). Aunque la pieza sólo la conocemos a través de un dibujo muy esquemático presente en la publicación original, abogamos por su inclusión dentro de esta clase de objetos, si bien podría tratarse también de un bronce de arnés.

\section{CARACTERÍSTICAS Y FUNCIONALIDAD}

Los «delantales» son uno de los elementos más característicos del equipo personal militar durante el siglo I d.C., como demuestran las abundantes representaciones iconográficas de estos objetos estudiadas por Bishop (1992, 81-104). Asociado a las tropas de infantería del ejército romano, está constituido por una serie de tiras de cuero, a menudo decoradas con apliques claveteados, como ilustra la correa encontrada en Mainz (fig. 6, n. ${ }^{\circ}$ 5; Lindenschmit, 1870) ${ }^{7}$. Dichas tiras suelen finalizar en unos terminales móviles cuyos pinjantes adop$\tan$ un pequeño repertorio de formas. Entre ellos, los luniformes, romboidales y en forma de «gota» son probablemente los más abundantes (fig. 5, n. $^{\text {os }}$ 1 y 2 ).

La función de estas correas auxiliares del cinturón ha sido muy discutida. Para algunos investigadores tendrían un cometido defensivo, como es el de proteger el bajo vientre de las armas de los ene-

${ }^{7}$ El ejemplar de Mainz se conoce por una publicación antigua, existiendo la duda de sí la correa de cuero es la original (Bishop, 1992, 92-93).

migos. No obstante, estamos de acuerdo con quienes cuestionan esta función, debido a la escasa protección que ofrecerían unas sencillas tiras de cuero reforzadas por endebles accesorios metálicos. Sobre todo si tenemos en cuenta que dichos accesorios suelen estar fabricados a partir de delgadas láminas de cobre/bronce. Como sugiere Bishop, es más probable que estén relacionadas con la demostración de un determinado status. Al igual que el cinturón siempre distinguió al soldado del civil durante todo el Imperio Romano, el «delantal» sería un elemento distintivo más, sólo que restringido a los primeros siglos. Nosotros creemos que ese fue el motivo por el que se plasmó tan a menudo en los monumentos funerarios individuales, ya que era representativo del status social del soldado. Igualmente, por ser un elemento de prestigio se depositó en las tumbas junto a su poseedor, como demuestra el hallazgo español de Aznalcázar. El carácter «lujoso» de algunas aplicaciones metálicas para «delantal», que presentan baño de plata, también avalaría está hipótesis. Tampoco se puede desdeñar una relativa función bélica derivada del sonido producido por el movimiento de cientos de estas correas. Es indudable que el ruido producido en el campo de batalla por estos objetos, unido al de los instrumentos musicales militares, podría influir en el ánimo del enemigo. Aunque en la vida civil, como dice Bishop, este sonido también serviría para manifestar la presencia de un soldado y distinguirla del resto de ciudadanos (Bishop, 1992, 100102). 


\section{LOS PINJANTES HISPANOS}

Las correas rematadas por pinjantes luniformes son un elemento decorativo corriente entre este tipo de accesorios. De entre las cuarenta y cinco representaciones escultóricas estudiadas por Bishop, al menos nueve de ellas tienen terminales de esta clase (Bishop, 1992, tabla 1). Estas piezas son difíciles de identificar cuando aparecen aisladas y no están acompañadas por otros elementos susceptibles de ser identificados como accesorios de «delantal». La semejanza entre los pinjantes usados en estas correas auxiliares del cinturón y los colgantes de arnés del tipo «Bishop 9», dificulta la clasificación de los ejemplares sueltos (Bishop, 1988, 98). Lo mismo podemos decir sobre los pinjantes secundarios en forma de «gota». Es por ello que el número de estas piezas halladas en contextos arqueológicos e identificadas como pertenecientes a correas de «delantales» es relativamente reducido. Ejemplares, como por ejemplo los procedentes de Bordeaux, señalados como elementos de arnés, han sido probablemente mal interpretados (Feugère, 1997, 131, fig. 11, n. ${ }^{\text {os }}$ 84-85). Las lunulae son los pinjantes más antiguos del mundo romano, quizá una aportación de la caballería céltica, y deben su popularidad a su fuerte simbolismo y a su carácter apotropaico. Su etapa de esplendor comprende un largo período, desde el reinado de Augusto hasta todo el siglo II (Bishop, 1988, 107-108).

El hallazgo de Aznalcázar cuenta con buenos paralelos fuera de nuestras fronteras. Un pinjante luniforme idéntico a los encontrados en el conjunto sevillano procede de Caerleon (fig. 6, n. ${ }^{\circ} 3$; Zienkiewicz, 1986, 181, n. ${ }^{\text {os }} 132$ y 182). El espécimen britano no sólo posee tres pinjantes secundarios, característica muy peculiar documentada en raras ocasiones, sino que su decoración punzonada presenta la misma sintaxis decorativa que en el caso de Aznalcázar. La misma ornamentación ostenta también el colgante hispano de Teba (Málaga). El ejemplar malagueño posee únicamente un subpinjante, si bien éste cuenta con un motivo decorativo gemelo a los subpinjantes de Caerleon. Todo ello nos lleva a pensar que los ejemplares de Aznalcázar, Teba y Caerleon pudieron salir de un mismo taller.

Los pinjantes de Aznalcázar se insertan en sendas placas que se sujetaban al cuero. Placas similares son las aparecidas en el «delantal» del archiconocido tesoro de Tekije (fig. 6, $\mathrm{n} .{ }^{\text {os }} 1$ y 2 ; Bishop, 1992, 93-94.). Las piezas serbias tienen otros puntos en común con las españolas, como son el par de apliques claveteados de las placas, la ornamentación punzonada (aunque en ellas difiere el esquema de- corativo) y los pinjantes secundarios en forma de «gota». Otro interesante hallazgo, similar al de Tekije y Aznalcázar lo encontramos en el «delantal» que acompañaba a un soldado aparecido en Herculano, hallazgo que lamentablemente no ha sido publicado en su totalidad (Bishop, 1992, 94).

La lúnula aparecida en el campamento de Herrera de Pisuerga es de un tipo algo más simple, pudiendo citarse para ella una gran cantidad de paralelos entre los accesorios metálicos para «delantales» reconocidos sin duda como tales. Casi idénticos son los pinjantes procedentes de Vindonissa (Unz; Deschler-Erb, 1997, 38, n. ${ }^{\circ} 1277$ y 1282), Darmstadt y Wroxeter (Bishop, 1992, fig. 16, 3 y 5). Mientras que otros colgantes luniformes similares son los de Colchester (Crummy, 1983, 164, n. ${ }^{\circ}$ 4621), Carnuntum (Stiglitz, 1987, 208, fig. 5, n. ${ }^{\circ} 2$ ), Magdalensberg (Deimel, 1987, 313, n. ${ }^{\text {ss }} 83$ y 84), Dangstetten (Fingerlin, 1986, 136) o Sala (BoubePiccot, 1994, 93, n. ${ }^{\circ}$ 136).

Respecto al terminal en forma de hoja de la tumba sevillana, no conocemos ningún otro pinjante semejante entre los accesorios para «delantales». No obstante dicha forma sí es habitual entre los bronces de arnés, siendo incluidos por Bishop en su tipo «4» (Bishop, 1988, 96). Los pinjantes de arnés con esta morfología son bien conocidos en Hispania, como por ejemplo el hallazgo de Velilla de Ebro (Bronces, 1990, 317, n. ${ }^{\circ} 295$ ), aunque ninguno nos serviría como paralelo exacto para Aznalcázar. Lo mismo podemos decir sobre los pinjantes romboidales, como el encontrado en Herrera. Algunas piezas similares, como las de Risstissen, son clasificadas como elementos de «delantales» (Bishop, 1992, fig. 16,2 y 4), mientras que otras se clasifican como bronces de arnés. Objetos similares son los colgantes de Aulnay-de-Saintonge, datados en los años veinte del siglo I (Feugère, 1993, 32, n. ${ }^{\circ}$ 7); Volubilis (Boube-Piccot, 1994, 94, n. ${ }^{\circ}$ 141); Vindonissa (Unz; Deschler-Erb, 1997, 43, n. ${ }^{\text {os }} 1432-1434$ ), o los españoles encontrados en Villas Viejas (Aurrecoechea, 1995/96, fig. 5, 5) y Numancia (Paulsen, 1931, 272, fig. 45).

Una vez vistos los paralelos queremos proponer la posible cronología y reconstrucción de los casos hispanos con lunulae, los únicos susceptibles de una interpretación más aquilatada. Todos los datos apuntan hacia la segunda mitad de la primera centuria como la temporalidad más probable. El pinjante aparecido en Herrera de Pisuerga parece estar fechado en esos años (Pérez, 1996, 91-92). El ocultamiento de Tekije está relacionado con los disturbios acaecidos en la Dacia entre el 83/89 d.C., siendo la moneda más reciente aparecida en el conjunto del 


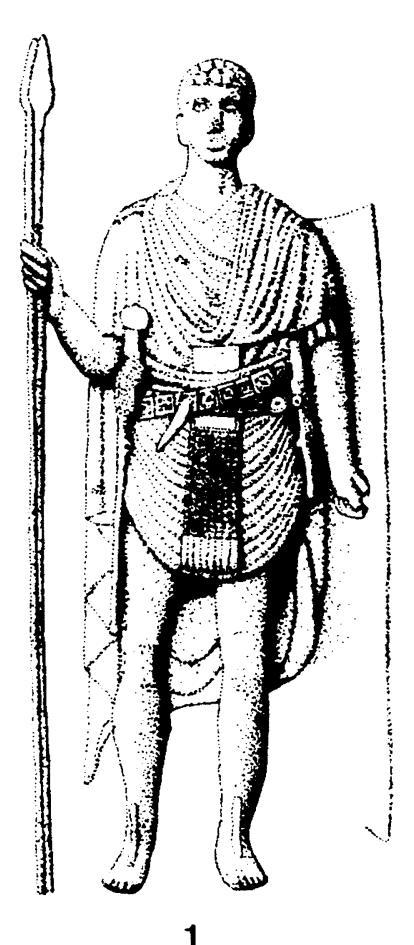

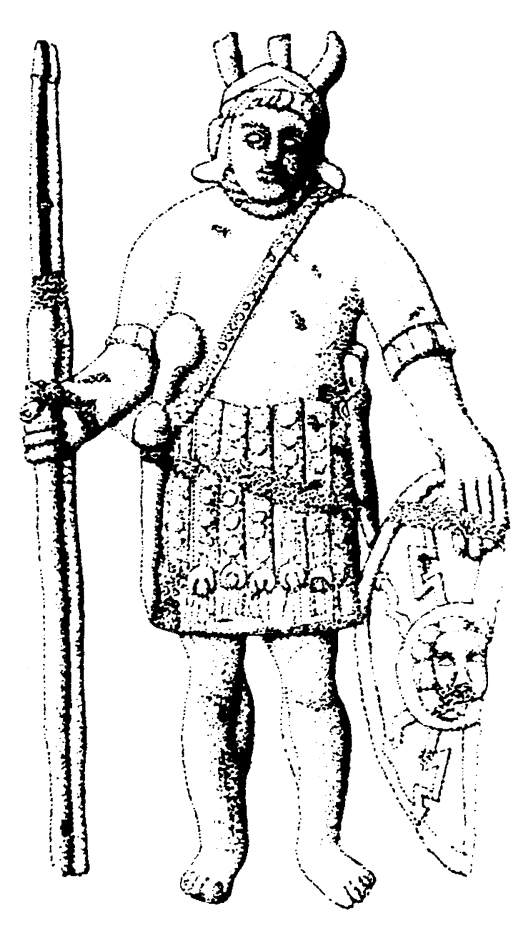

2

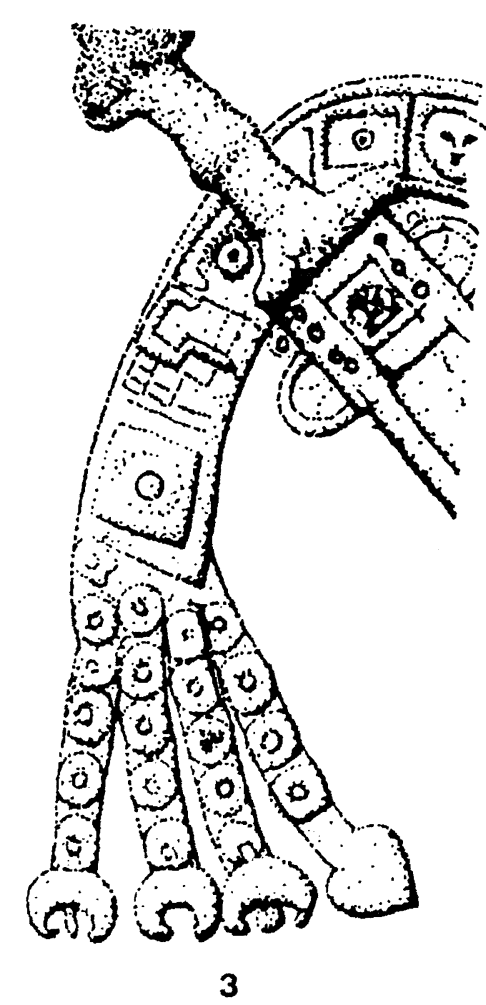

3

Fig. 5.-1, estela del auxiliar Annaius Daverzus (Bingen). 2, estela de Castricius Victor (Aquincum). 3, relieve de Pula. Según Bishop. Sin escala.

reinado de Domiciano. El soldado de Herculano murió sin duda en la explosión volcánica del año 79. Caerleon nos ofrece una fecha post quem, ya que el fuerte legionario es una fundación flavia para establecer a la Legio II Augusta hacia el año 75 d.C. Podemos incluso asegurar que los especímenes españoles son de tiempos flavios, pues a las consideraciones de índole arqueológica se suman otras de tipo iconográfico. Según se puede constatar por las fuentes escultóricas, el número y la disposición de las correas de los «delantales» sufren una lenta pero constante evolución, desde las representaciones iniciales coetáneas a los primeros momentos del siglo I, hasta los últimos relieves fechados en el primer cuarto de la segunda centuria. Si tenemos en cuenta que en la tumba de Aznalcázar aparecieron cuatro pinjantes luniformes más uno en forma de «hoja», y consideramos que los cinturones que se complementaban con un «delantal» solían contar también con un terminal que se situaba en el extremo del cíngulo opuesto a la hebilla, podemos aventurar que el hallazgo sevillano constaba de un «delantal» formado por cuatro correas y un cinturón con el remate vegetal. Los «delantales» constituidos por cuatro correas terminadas en lunulae aparecen ocasional- mente en época claudio-neroniana, como documentan las estelas sepulcrales de Q. Petilius Secundus, Pintaius, etc. (Bishop, 1992, n.$^{\text {os }} 5$ y 7), pero son característicos del período flavio (Bishop, 1983, 30, nota 27). Pertenecientes a esta última dinastía son la mayoría de las representaciones iconográficas asimilables a Aznalcázar, como por ejemplo las estelas de Genialis, C. Valerius Crispus, etc. (Bishop, 1992, n. $^{\text {os }} 16,17,23$ y 24). Un dato que queremos reflejar es que, en ocasiones, el «delantal» no estaba formado por una serie de correas independientes del cinturón, sino que formaban parte del mismo mediante la ramificación del extremo de la correa. De Pula procede un relieve que nos sirve para ilustrar el modo en que estos «delantales» se constituían, pues a menudo no son más que sendas tiras que parten del extremo del cíngulo, pasándose una de ellas a través de la hebilla para cerrar el cinturón y dejándose caer el resto hasta colgar armoniosamente sobre el bajo vientre (fig. 5, n. ${ }^{\circ} 3$ ). Precisamente el relieve de Pula podría servir de paralelo para Aznalcázar, pues combina remates luniformes con subpinjantes y un terminal acorazonado, siendo presuntamente este último el que serviría para cerrar el cinturón (Bishop, 1992, n. $\left.{ }^{\circ} 44\right)$. 


\section{LOS APLIQUES CLAVE- TEADOS HISPANOS}

En Hispania, como en otros lugares del Imperio Romano, son muy frecuentes los apliques claveteados, sobre todo los de cabeza circular. Aunque Bishop defiende la hipótesis de que, entre estos últimos, aquellos que poseen círculos concéntricos moldurados son característicos de los «delantales» militares (Bishop, 1992, 96), la realidad es que determinar la función de estas piezas tan simples es imposible, ya que objetos similares se emplearon en los elementos de atalaje, mobiliario, etc. Aunque seguramente algunos de los hallazgos hispanos fueron usados para decorar las tiras de estos «delantales», no podemos discernir cuáles de ellos son, ni tan siquiera cuando son encontrados en campamentos militares. Sólo los que tienen decoración figurada, como los de Teba (Málaga), pueden ser identificados con seguridad como pertenecientes a las correas que analizamos en nuestro estudio. Ulbert y Feugère han sido los dos investigadores que se han ocupado de este tipo de piezas. El investigador francés sugiere la hipótesis de que los apliques claveteados con decoración en relieve fueron producidos en talleres oficiales, siendo Besançon el taller principal a tenor de la concentración de hallazgos, constituyendo regalos oficiales dados a los soldados como propaganda imperial ante eventos especiales (Feugère, 1985, 117-141). Su periodo de fabricación sería muy corto, comprendiendo la segunda mitad
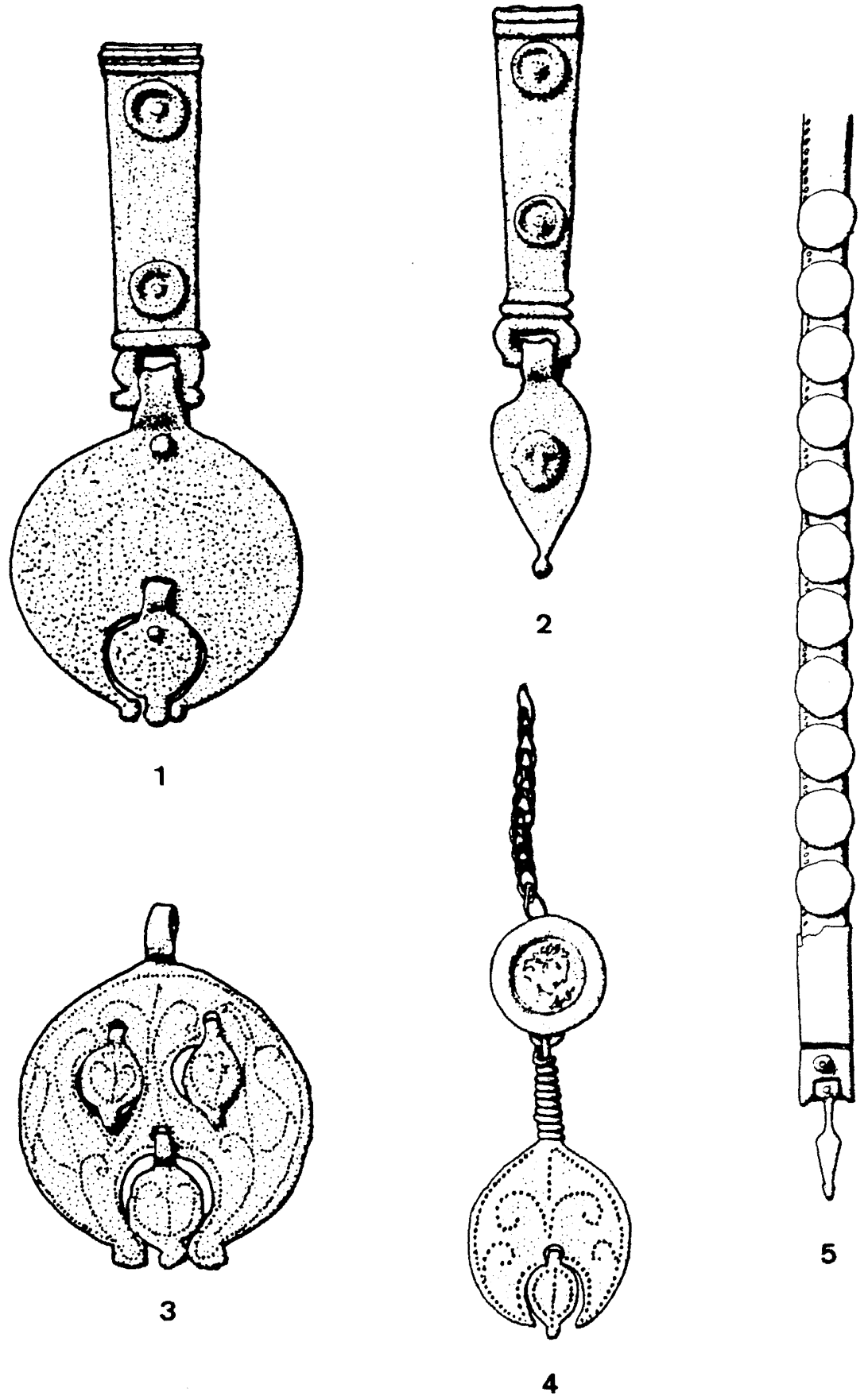

Fig. 6.-1 y 2, tesoro de Tekije. 3, pinjante de Caerleon. 4, colgante de Londres. 5, correa de Mainz. Según Bishop, a excepción del n. ${ }^{\circ} 4$ según Feugère. Sin escala. del siglo I d.C., concentrándose temporalmente durante la dinastía flavia, aunque pudieron estar en uso hasta el reinado de Trajano. Dichos apliques se sujetaban directamente a las tiras de cuero, aunque también podían insertarse en las cadenitas que en 


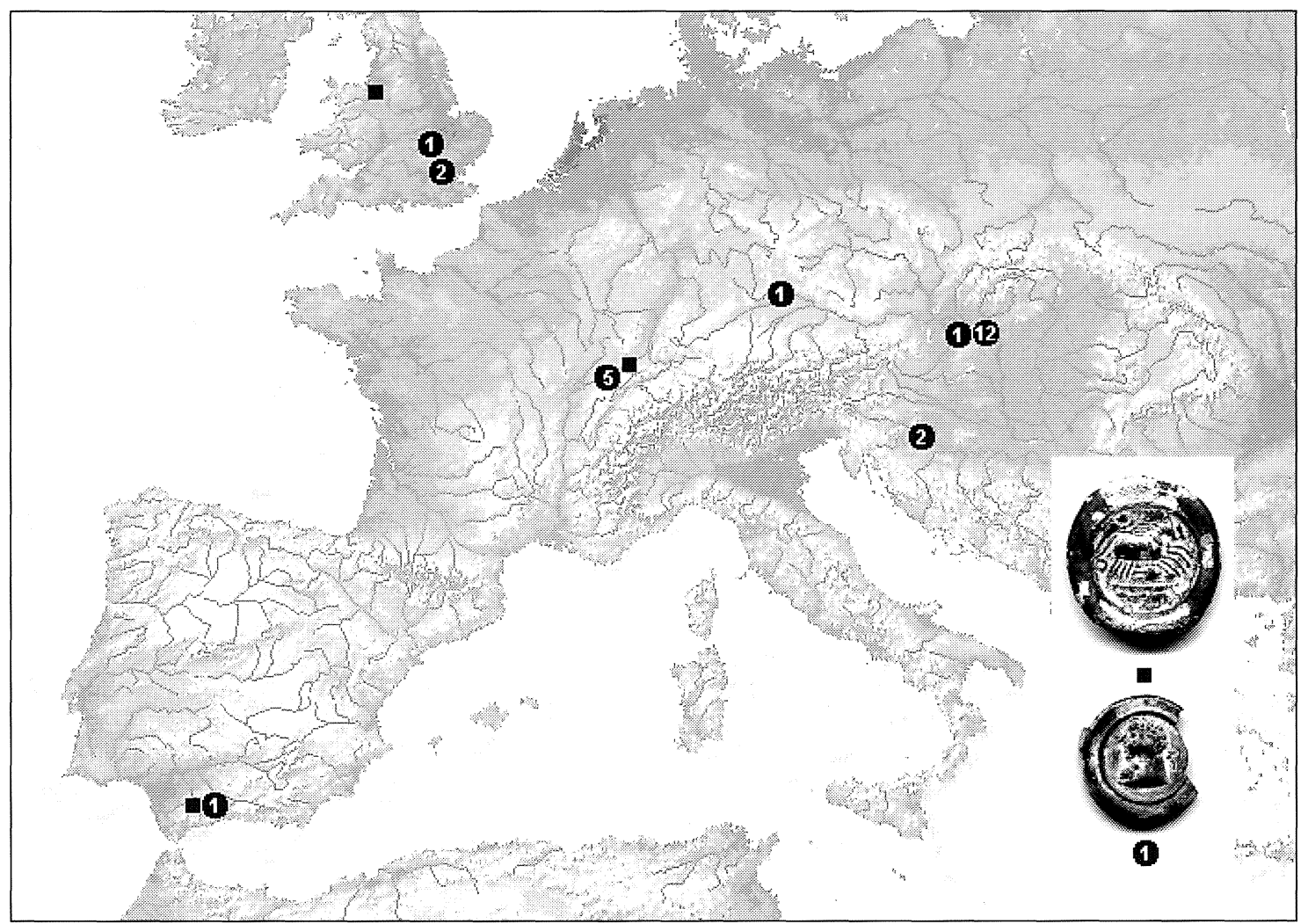

Fig. 7.-Mapa con distribución de los apliques claveteados del tipo «Feugère 9» y «Feugère 17». Los números hacen alusión a la cantidad de piezas asignadas a la primera categoría.

ocasiones sirven para suspender los pinjantes (fig. 6, n. $\left.^{\circ} 4\right)$.

Centrándonos en los apliques hispanos, éstos son los ejemplares encontrados más al sur de Europa, muy alejados del limes septentrional del Imperio, lugar donde son característicos. El aplique ornamentado con un busto imperial de perfil hacia la izquierda (fig. 3 , n. ${ }^{\circ} 4$, y 4 ) pertenece al tipo «Feugère 9», conociéndose hallazgos muy similares en Londres (2 ejemplares), Verulamiun, Pfünz, Besançon (5 apliques), Szöny-Brigetio, Kaloz (12 ejemplares) y Siscia (2 especímenes) (Feugère, 1985, 128, fig. 7). Los apliques decorados con una biga se engloban en el tipo «Feugère 17». Esta última categoría es mucho menos abundante que la anterior, ya que sólo se conocían un par de piezas encontradas en Chester y Montbéliard (Feugère, 1985, 131), a las que ahora hay que sumar la de Teba (fig. 3, n. $^{\text {s }} 3$ y 4 ). Dadas las coincidencias formales y dimensionales, casi podemos asegurar que los ejemplares de Chester y Teba fueron realizados con el mismo punzón. El bronce malagueño goza de un estado de conservación excelente, lo que nos permite realizar algunas apreciaciones iconográficas que aún no habían sido expuestas. La figura que conduce el carro puede ser identificada como una Victoria, pues de su espalda surge un ala vista de perfil. Debajo de las patas de los caballos se encuentra una figura humana tendida en el suelo, lo que nos permite reconocer la escena como una Victoria arrollando al enemigo. El paralelo de Chester, fuerte de época flavia donde se estableció la Legio II Adiutrix Pia Fidelis, entre mediados de los años 70 y finales de la década de los 80 d.C., nos podría indicar una fecha post quem para estos especímenes. Por último mencionaremos el aplique romboidal encontrado también en Teba (fig. 3, n. $^{\circ}$ ), para el que desconocemos otros paralelos. Su decoración estampada encaja en la categoría que analizamos, aunque también existen marcadas diferencias que nos hacen dudar de su adscripción correcta, pues el motivo iconográfico representado es una cabeza y no un busto, la forma del objeto es romboidal y además está constituido por dos piezas (una placa argéntea con la ornamentación mencionada superpuesta a un aplique de cobre/bronce). No obstante, aunque su pertenencia a las correas auxiliares que tratamos es dudosa, creemos que este objeto pudo formar parte también de 
los regalos oficiales realizados a los soldados durante la dinastía flavia.

\section{CONCLUSIONES}

Después de analizar este apartado del equipo militar, los resultados nos incitan a formularnos una pregunta: ¿por qué aparecen estos elementos metálicos en la Hispania de la segunda mitad del siglo I d.C.? Según nuestra fase actual de conocimiento, los hallazgos no parecen estar relacionados necesariamente con establecimientos militares, si exceptuamos algunos casos como Herrera de Pisuerga, si bien este es un dato que podría cambiar cuando se den a conocer los objetos aparecidos en las recientes excavaciones de fuertes militares. Además, desde la guerra cántabro-astur Hispania es una provincia pacíficada ${ }^{8}$ en la que apenas hay tropas regulares, salvo las que en la provincia Citerior estaban al mando del legatus Augusti propraetore (las legiones IV Macedonica, VI Victrix y X Gemina en un primer momento). Si a estas circunstancias le sumamos la aparición de bronces de este tipo por la romanizada Bética, incluida una sepultura, comprenderemos la necesidad de dar una interpretación al fenómeno. Una de las posibles respuestas podría ser el reclutamiento de auxilia y legionarios hispanos durante este siglo, como por ejemplo el ala II Flavia Hispanorum Civium Romanorum, la cohors II Astutum Equitata (por citar dos formadas en época flavia) y otras muchas ${ }^{9}$. Numerosos hispanos pasaron a formar parte del ejército en esa época y posiblemente cuando volvían a casa algunos de ellos traían objetos de su vida militar (muy probablemente el balteus o cinturón y el «delantal» que lo complementaba). Sin embargo, la concentración de especímenes en el periodo flavio puede tener un significado más concreto. Durante la guerra por el poder del año 69 y el comienzo del reinado de Vespasiano, en Hispania hubo un movimiento de legiones que no volvería a repetirse en mucho tiempo. En este periodo se añadió a la VI Victrix (única estable que quedaba en Hispania, tras los traslados en el 39 de la IV Macedonica y en el 63 de la X Gemina) la Legio I Adiutrix; además se reclutó una nueva legión (VII Gemina) y la X Gemina volvió del limes. Esos años son propicios para la aparición de objetos como los que estudiamos, pues la concentración de

\footnotetext{
${ }^{8}$ Durante este periodo sólo se conoce la represión de una sublevación de los Astures hacia la mitad de los años 50.

${ }^{9}$ Mencionamos únicamente a los auxilia y no a los nume$r i$, porque de estas últimas tropas de carácter nacional solo se conoce un cuerpo español, el de los symmachiarii Astures que participó en las guerras dácicas en tiempos de Cómodo.
}

tropas en Hispania, el reclutamiento de contingentes militares y el posible establecimiento de veteranos en nuestro suelo, pudo traducirse en una mayor aparición de equipo militar datado entre el 69 y toda la época flavia. Precisamente la instalación de algunos veteranos (hispanos o no hispanos) quizá explique también estos hallazgos. La aparición de epigrafía, como por ejemplo algunos diplomas militares, podría confirmar esta hipótesis. Estos soldados afincados en Hispania no sólo sirvieron en el lejano limes germano, sino también en la cercana África, como atestigua el diploma militar encontrado en Baelo Claudia (Cádiz) correspondiente a la cohors prima Ituraeorum y datado en época algo posterior (161 d.C. Jacob, 1984). El hallazgo en Marruecos de elementos metálicos para «delantales» similares a los hispanos nos hace pensar en el flujo humano entre estas dos regiones. Tampoco podemos desechar una última teoría. La organización militar de la Península Ibérica se completaba con una serie de milicias, en cierto modo extraordinarias, ya que no encajan en el marco del ejército regular, a las que se les ha dado la etiqueta de tropas provinciales o municipales. Entre ellas hemos de citar las cohortes orae maritimae, cuya función era proteger el litoral mediterráneo, y las fuerzas militares en la provincia senatorial de la Baetica, como eran la cohors Baetica y la cohors Servia Iuvenalis (Ritterling, 1927). ¿Pudieron pertenecer algunos de estos bronces militares a estas tropas de carácter local? Cualquiera de las hipótesis planteadas podría ser válida, sólo el tiempo y las nuevas investigaciones confirmarán alguna de ellas.

\section{BIBLIOGRAFÍA}

Aurrecoechea, J., 1995/96: «Las guarniciones de cinturón y atalaje de tipología militar en la Hispania romana, a tenor de los bronces hallados en la Meseta Sur». Estudios de Prehistoria y Arqueología Madrileñas, 10.

Bishop, M.C., 1983: «The Camomile Street soldier reconsidered». Transactions of the London and Middlesex Archaeological Society, 34.

Bishop, M. C., 1988: «Cavalry equipment of the Roman Army in the first century A.D.». Military Equipment and the Identity of Roman Soldiers. B.A.R. International Series, 394.

Bishop, M.C., 1992: «The early imperial «apron». Journal of Roman Military Equipment Studies, 3.

Bronces, 1990: Bronces romanos en España: catálogo de la exposición. Madrid, 1990.

Boube-Piccot, C., 1994: L'équipement militaire et 
l'armement. Les bronzes antiques du Maroc, IV. Paris, 1994.

CoRpus, 1996: Corpus de inscripciones latinas de Andalucía. Volumen II (Sevilla), Tomo IV (El Aljarafe, Sierra Norte, Sierra Sur). Sevilla, 1996.

CRummy, N., 1983: The Roman small finds from excavations in Colchester 1971-79. Colchester Archaeological Report, 2. London 1983.

Deimel, M., 1987: Die Bronzekleinfunde vom Magdalensberg. Klagenfurt, 1987.

FERnÁndez Ruiz, J., 1981: «Hallazgo de un togado en Teba (Málaga)». Baetica, 4.

Fernández Ruiz, J; Rodríguez Oliva, P., 1978: «Nuevos documentos epigráficos y numismáticos». Jabega, 22 (4).

FeugÈre, M., 1985: «Nouvelles observations sur les cabochons de bronze estampes du cingulum romain». The Production and Distribution of Roman Military Equipment. B.A.R. International Series, 275.

Feugère, M., 1993: Les armes des romains. Paris, 1993.

FeugÈre, M., 1997: «Le petit mobilier». Les fouilles de la place des Grands-Hommes à Bordeaux. Pages d'Archéologie et d’histoire Girondines, 3, 1997.

Fingerlin, G., 1986: Dangstetten 1. Stuttgart, 1986.

García Alonso, E., 1993-1994: «Los Castillejos de Teba (Málaga). Excavaciones de 1993. Estratigrafía de los siglos VIII-VI a.C.». Mainake, 1516.

García Díez, F., 1999: «Algunas piezas metálicas romanas de Herrera de Pisuerga». Papeles Herrerenses, 2.

Hernández Díaz, J.; Sancho Corbacho, A.; CollanTES DE TERÁN, F., 1939: Catálogo arqueológico y artístico de la provincia de Sevilla, Tomo I. 1939.

IllARREGUi, E., 1999: «Una anilla de arnés procedente de las excavaciones de la Avenida de Eusebio Salvador, Herrera de Pisuerga». Papeles Herrerenses, 2.

$\mathrm{J}_{\mathrm{ACOB}}$, P., 1984: «Un diploma militaire romain a Baelo Claudia (Tarifa, province de Cadix)». Melanges de la Casa de Velázquez, 20.
Lindeschmitt, L., 1870: Die Altertümer unserer heidnischen Vorzeit, Bd. 4. Mainz.

PAulsen, R., 1931: «Die Funde von Numantia». En Schulten, A. Die Stadt Numantia. Numantia 2. Munich 1931.

Pérez, C., 1995: «Una testera militar de caballo en bronce de época augustea en España». Anuario de la Universidad Internacional SEK, 1.

Pérez, C., 1996: «Asentamientos militares en Herrera de Pisuerga». Los finisterres atlánticos en la antigüedad. Madrid, 1996.

Recio, A., 1988: «El Hermes de Teba». Mainake, 10.

Recio, A., 1991-1992: «Figuraciones zoomorfas y antropomorfas en la cerámica ibérica pintada malagueña». Mainake, 13-14.

RitTerling, E., 1927: «Military forces in the senatorial province». Journal of Roman Studies, 17.

Rodríguez Oliva; Atencia, R., 1986: «El retrato de Tiberio del Cortijo del Tajo (Teba, Málaga)». Baetica, 1986, 9.

Romagosa, J., 1969: «Notas sobre las monedas de Olontigi». Gaceta Numismática, 13.

Serrano, E.; Atencia, R.; Luque, A., 1985: «Memoria de las excavaciones del yacimiento arqueológico de «El Tesorillo» (Teba, Málaga)». Noticiario Arqueológico Hispánico, 26.

Serrano, E.; Gómez, A.; Castaños, J., 1992: «Un nuevo taller de sigillata en la Baetica: Teba (Málaga)». Baetica, 14.

SolÀ Solè, J.M., 1965: «Acuñaciones monetarias de Olontigi». Numisma, 74.

Stiglitz, H., 1987: Auxiliarkastell Carnuntum. Carnuntum Jarhbuch 1986 (1987).

Thouvenot, R., 1927: Catalogue des figurines et objets de bronze du Musée Archéologique de Madrid, I. Bronzes grecs et romains. Bibliotèque de l'Ecole des Hautes-Etudes Hispaniques, 12.

Unz, C.; Deschler-Erb, E., 1997: Katalog der Militaria aus Vindonissa. Veröffentlichungen der Gesellschaft pro Vindonisa, Band XIV, 1997.

Zienkiewicz, J.D., 1986: The finds. The Fortress Baths at Caerleon 2. Cardiff, 1986. 